\title{
Developing a framework of Quaternary dune accumulation in the northern Rub' al-Khali,
} Arabia.

\author{
Andrew R Farrant ${ }^{\mathrm{a}}$, Geoff A T Duller ${ }^{\mathrm{b}}$, Adrian G Parker ${ }^{\mathrm{c}}$, Helen M Roberts ${ }^{\mathrm{b}}$, Ash Parton ${ }^{\mathrm{d}}$, Robert W \\ O Knox ${ }^{\text {a\# }}$, and Thomas Bide ${ }^{\mathrm{a}}$.
}

${ }^{a}$ British Geological Survey, Keyworth, Nottingham, NG12 5GG, UK. arf@bgs.ac.uk [corresponding author 0115 9363184].

${ }^{\mathrm{b}}$ Aberystwyth Luminescence Research Laboratory, Department of Geography \& Earth Sciences, Aberystwyth University, Aberystwyth, SY23 3DB, Wales, UK

${ }^{\mathrm{c}}$ Department of Social Sciences, Faculty of Humanities and Social Sciences, Oxford Brookes University, Oxford, OX3 0BP, UK

${ }^{\mathrm{d}}$ Research Laboratory for Archaeology and the History of Art, School of Archaeology, University of Oxford, Oxford, OX1 2HU, UK

\#Deceased

\begin{abstract}
Located at the crossroads between Africa and Eurasia, Arabia occupies a pivotal position for human migration and dispersal during the Late Pleistocene. Deducing the timing of humid and arid phases is critical to understanding when the Rub' al-Khali desert acted as a barrier to human movement and settlement. Recent geological mapping in the northern part of the Rub' al-Khali has enabled the Quaternary history of the region to be put into a regional stratigraphical framework. In addition to the active dunes, two significant palaeodune sequences have been identified. Dating of key sections has enabled a chronology of dune accretion and stabilisation to be determined. In addition, previously published optically stimulated luminescence (OSL) dates have been put in their proper stratigraphical context, from which a record of Late Pleistocene dune activity can be constructed. The results indicate the record of dune activity in the northern Rub' al-Khali is preservation limited and is synchronous with humid events driven by the incursion of the Indian Ocean monsoon.
\end{abstract}

Keywords: Arabia, dunes, palaeoclimate, OSL dating, United Arab Emirates, Monsoon.

\section{Introduction}

Reconstructing environmental change in Arabia is vital for improving our understanding of the context for demographic variability during the Mid-Late Pleistocene (Groucutt and Petraglia, 2012). During much of this time, the presence of the hyper arid Rub' al-Khali desert presented a major environmental barrier for human dispersal. However, fluctuations in the regional climate, driven by the varying latitudinal interface between the south-westerly Indian Ocean Summer Monsoon (IOSM) and the Westerly driven Shamal winds, created occasional humid interludes generating the potential for human migration across this region. Although IOSM rainfall is currently restricted to southern coastal regions of Yemen and Oman, at times it increased in strength and penetrated much further north across Arabia, bringing moist conditions across the now hyper-arid Rub' al-Khali (Fleitmann et al., 2007; Rosenberg et al., 2011; Atkinson et al., 2013). Constraining the timing of these moist incursions is essential for determining when human migration may have occurred (Armitage et al., 2011; Parton et al., this issue). However, this necessitates having high-quality palaeoclimatic records from the region, combined with good chronological control. One such source of palaeoclimatic information are the Quaternary sediments that occupy the Rub' al-Khali basin. This region (Figure 1), which extends over $600,000 \mathrm{~km}^{2}$ and covers one-third of the Arabian subcontinent (Edgell, 2006; White et al., 2001), has an extensive cover of Quaternary deposits. These mostly comprise aeolian dune systems with a suite of alluvial fans along the margins of the Hajar Mountains, and localised palaeolakes and inland sabkhas (Farrant et al., 2012a). The importance of these Quaternary sediments 
lies in their capacity to document palaeoclimatic changes over the last few hundred thousand years. Most attention has been focused on palaeolake sequences (e.g. Parker, 2010; Parton et al., 2013; Rosenberg et al., 2012, 2013; Crassard et al., 2013) and speleothems from cave systems in adjacent upland areas (Burns et al., 2001; Fleitmann and Matter 2009). With the notable exception of the northeastern fringe of the desert and the Liwa oasis the aeolian record from this region has been comparatively underutilised. The application of luminescence dating techniques to the active and relict dune fields within the Rub' al-Khali basin addresses this, and provides evidence for past climates and environments where dated palaeolake and speleothem records are scarce.

Extracting a palaeoclimatic record from aeolian sequences is not straightforward (Chase, 2009). Many factors influence dune accretion, migration and stabilisation (Thomas and Burrough, 2012; Leighton et al., 2013), notably sediment supply, the transport capacity of the wind and sediment availability (Preusser, 2009). The latter is a function of vegetation, soil moisture, and the position of the water table. Consequently, periods of dune accretion are often used to infer aridity whilst dune stabilisation is usually associated with reduced wind speed or increased vegetation or cementation - both indicators of more humid conditions. Across much of the UAE, generally unimodal north-westerly Shamal wind regimes (Barth, 2001) favour barchan or transverse dune forms. As these dunes migrate, each phase of dune activation may remove evidence of earlier forms, particularly where the sediment supply is limited by high groundwater and sea levels, and the rate of deflation of sand from older deposits is low (Goudie et al., 2000). This can lead to discontinuous sediment records. Higher resolution stacked records are more common towards the eastern and southern borders of the UAE where sand accumulates as star dune or dune ridge complexes along the eastern margin of the dune field. Stacked dune sequences also occur where dunes become rapidly lithified or develop cemented palaeosols. This is common in carbonate-rich dunes such as the Wahiba sands (Preusser et al. 2002, Radies et al. 2004), and those preserved along the Persian Gulf coast (Teller et al., 2000, Farrant et al., 2012a).

Interpreting optically stimulated luminescence (OSL) ages from dune sequences can also be problematic. OSL ages record the last time sand was exposed to daylight (Duller 2004). During periods of active dune migration, the dune's luminescence clock is constantly reset by sediment recycling and systematic self-cannibalisation. Dates from dormant and stable palaeodunes therefore do not usually reflect periods of aeolian activity and accretion, but rather the timing of dune stabilisation. In addition, there is a lag time between dune deposition and stabilisation, dependant on the sediment turnover rate known as the dune 'reconstitution' time (Allen, 1974; Lancaster, 2008). This is generally greater for large dune forms than smaller, more mobile dunes (Stone and Thomas, 2013). This is important when considering the timing of dune preservation. OSL ages from migrating barchan-type dunes stabilised at the onset of humid conditions can span a few thousand years depending on the rate of sediment turnover and the depth of the OSL sample. For accurately defining periods of dune stabilisation, dunes with short reconstitution times and high preservation potential, such as small carbonate dunes, are the most useful. Equally important are the gaps in the chronological record. These can either mean arid periods with extensive dune recycling or periods of sustained rainfall with minimal dune activity.

To gain a full appreciation of the palaeoclimatic record, a large OSL data set with a broad temporal and spatial coverage is required. Over reliance on a small or local dataset can lead to the misinterpretation of complex regional palaeoenvironmental changes by over-emphasising local factors. Spatially extensive datasets can also begin to overcome the issue of regional climatic variation; are climate events synchronous or of the same duration throughout the region, or do they vary in time and space, dependant on the local environment? 
To date, attempts to establish a regional dune chronology in the northern Rub' al-Khali have been hampered by the lack of a clear regional geological context in which the deposits can be set. In particular, the interplay and chronology of alluvial fan, fluvial wadi systems and dune fields has hitherto not been clearly understood. Recent geological mapping by the British Geological Survey (BGS) for the UAE Ministry of Energy (Styles et al., 2006, Farrant et al., 2012a); augmented by a suite of OSL dates, has for the first time provided a detailed geological framework for the Quaternary sediments in the northern part of the Rub' al-Khali (Farrant and Ellison, 2014). This enables stratigraphical relationships between multiple dune sequences, alluvial fans and wadi deposits across the Emirates to be deduced (Figure 2). Although it has long been recognised that the dune fields of the Rub' al-Khali comprise distinct sectors characterised by different dominant dune morphologies (Glennie and Singhvi, 2002; Bray and Stokes, 2003, 2004; Stokes and Bray 2005; Atkinson et al., 2012; Farrant et al., 2012a), what has not been generally recognised is the presence of extensive palaeodune sequences which provide evidence of earlier dune accumulation phases which underlie many of the more recent unconsolidated dunes or in some cases are coeval with them.

Prior to the BGS mapping of the UAE, the spatial coverage of published OSL dune samples (Table 1) across the northern Rub' al-Khali was poor (Figure 3). Most previous studies were concentrated in a relatively narrow strip on the eastern fringe of the dune-field in the far northeast of the UAE between Ras al Khaimah, and Al Ain (Goudie et al., 2000; Parker and Goudie, 2007, 2008; Atkinson et al., 2011, 2012, 2013; Leighton et al., 2013, 2014) and in the Liwa/al-Qafa region in Abu Dhabi emirate (Stokes and Bray, 2005). Glennie and Singhvi (2002) sampled a few sites across Abu Dhabi emirate, but provided little context for the dates, nor gave accurate locations. Moreover, these studies have for the most part focussed on the younger unconsolidated dunes (Figure 4), with the exception of Stokes and Bray (2005) who sampled some of the underlying palaeodunes.

Here we provide the results of a wide-ranging OSL dating program across the northern part of the Rub' al-Khali. We compare the results of this with existing published data to provide a regional framework for dune accretion, migration and stabilisation, and to characterise the temporal, spatial and chronostratigraphic variability of palaeodune sequences across this part of Arabia. The UAE was chosen as deflation along the upwind margin of the dune field exposes older palaeodune sequences which are poorly exposed further south. Moreover, ongoing urban development has created many sections though dune sequences, allowing their stratigraphic relationships to be examined in detail.

\section{Regional setting and stratigraphic framework}

The Quaternary deposits of the northern Rub' al-Khali desert consist of unconsolidated dunes, weakly cemented palaeodunes and alluvial fan sediments, with some marine and littoral sediments along the Persian Gulf coast. These deposits are underlain by a thick Neogene carbonate and siliciclastic sequence which is well exposed in outcrops along the coast west of Abu Dhabi. In the west, the Neogene succession is dominated by the Miocene-Pliocene fluvial and palaeodune sandstones of the Shuwaihat, Baynunah and Hofuf formations (Farrant et al., 2012a), and east of Abu Dhabi by Miocene ophiolitic conglomerates of the Barzaman Formation (Styles et al., 2006, Lacinska et al., 2014).

\subsection{Unconsolidated dune forms.}

The northern Rub' al-Khali is dominated by unconsolidated dune sands characterised by distinct dune morphologies. Along the upwind, coastal fringe of the Rub' al-Khali dune-field, the dunes are typically small barchanoid dunes or elongate linear dunes. Inland, these dunes get gradually larger, progressively burying the Miocene bedrock and older palaeodune outcrops, culminating in the large barchanoid dune forms across much of the central and eastern Emirates. Along the eastern fringe of 
the dune-field, the dunes are arranged in a suite of large-scale dune ridges. These attain heights of up to $70 \mathrm{~m}$ and extend laterally over tens of kilometres. Around Ras al Khaimah these dunes are oriented SW-NE, but further south, they trend NNW-SSE. Across the central swath of Abu Dhabi emirate, dune morphologies gradually transform downwind from coastal low dunes through extensive sandsheets and hooked barchan dunes, merging southwards into large coalesced transverse dunes 15$60 \mathrm{~m}$ high. Small interdune outcrops reveal underlying strata. A sharp crescentic boundary marks the boundary with the Liwa oasis, characterized by mega-barchanoid dunes up to $160 \mathrm{~m}$ high, superimposed by smaller barchan dunes 5-15 m high (Stokes and Bray, 2005, Embabi, 1991). Between these dunes are interdune sabkhas $2-3 \mathrm{~km}$ wide, which locally have low mesas and outcrops of weakly cemented palaeodunes. In the far southeast, dune ridges with star dunes mark the leading edge of the dune-field. The dune lithology also progressively changes south and eastwards from carbonate dominated sands on the coast to increasingly siliciclastic sediments further south. This reflects both the increasing contribution of sand from the underlying Neogene sandstones and the comminution of carbonate grains in transport.

\subsection{Quaternary Palaeodunes}

Relict palaeodune outcrops occur widely across the UAE and into adjacent parts of south-eastern Saudi Arabia. Two distinct units can be identified, the Madinat Zayed and Ghayathi formations (Figure 2).

\subsubsection{Ghayathi Formation}

The Ghayathi Formation comprises a distinctive suite of moderately to well-cemented carbonate-rich dunes (Farrant et al., 2012a) that crop out extensively in a zone along and a short distance inland from the coast, often forming wind eroded and deflated outcrops. These calcarenites, previously known as 'miliolite' (Glennie and Singvi, 2002), contain abundant bioclasts including corals, ooids, and shell fragments. These indicate a marine origin for the sediment, suggesting these dunes were formed from carbonate sediment blowing in from the Persian Gulf (Teller et al., 2000). Moreover, the heavy mineral signature of the minor siliciclastic component are significantly different from both the Miocene sediments and dune sands to the south, but are similar to sediments from the Persian Gulf (Farrant et al., 2012a; Garzanti et al., 2014). Near the coast, the carbonate content is typically around $80-90 \%$, but decreases rapidly inland partly due to dilution by siliciclastic input and partly by attrition. Further along the Gulf coast, in eastern Saudi Arabia, the lateral equivalent of the Ghayathi Fm is termed the Dammam aeolianite (Hussein, 2006).

Quarry and road cutting sections around Abu Dhabi and Dubai (Farrant et al., 2012b,c) often show two or more units of dune cross-bedded carbonate grainstones (Figure 5). It is clear from these sections that the Ghayathi Formation consists of more than one generation of aeolian deposits, each formed during one or more arid periods during the Quaternary and subsequently cemented in ensuing humid periods. These dunes cement rapidly in wet periods due to the meteoric leaching of unstable aragonitic material, which is reprecipitated as inter-granular, meniscus vadose cement, along with gypsum. This rapid cementation is confirmed by OSL dating (Farrant et al., 2012b), which indicate the most recent phase of carbonate dune deposition, cementation and stabilisation occurred during the early Holocene. These aeolianites form the core of the palaeodune ridges in the Dubai area (Farrant et al., 2012c), but gradually merge into unconsolidated dune ridges to the northeast towards Ras al Khaimah. Around Abu Dhabi, they form the nucleus of the barrier islands around which the Holocene marine and supratidal sediments were subsequently deposited (Evans et al., 2011).

\subsubsection{Madinat Zayed Formation}


The second palaeodune sequence, the Madinat Zayed Formation (Farrant et al., 2012a), comprises a thick sequence of siliciclastic palaeodunes that crops out across much of central and southern Abu Dhabi emirate, extending south into Saudi Arabia. This sequence of aeolian and playa sandstones and calcareous siltstones is up to 50-60 m thick and sourced largely from the Miocene Baynunah and Shuwaihat formations which crop out along the Gulf coast. Four distinct lithofacies can be identified: a reddish brown horizontally bedded, laminated sandstone; reddish brown aeolian dune cross bedded sandstone; thinly bedded and laminated pale grey calcareous siltstone and fine sandstones with local plant debris and algal stromatolites; and massive grey-green burrowed and rooted sandstone. The first two are aeolian, whilst the latter clearly indicate wetter, lacustrine environments. However along its eastern margin the Madinat Zayed formation is largely buried beneath younger deposits and merges imperceptibly with the fluvial Hili Formation (mainly distal alluvial fan deposits extending out from the Hajar Mountains), which is its lateral equivalent. Along the upwind northern edge of the outcrop, these palaeodunes rest unconformably with a marked irregular erosion surface on the Late Miocene Baynunah Formation. Between Ghayathi, Madinat Zayed and Sahil, the northern edge of the Madinat Zayed Formation outcrop is characterised by a highly degraded and deflated scarp with many prominent mesas rising up to 30-40 $\mathrm{m}$ above the surrounding desert. These are locally draped by both unconsolidated active dunes and Ghayathi Formation outcrops. Further south, outcrops of the Madinat Zayed Formation are limited to small interdune deflation hollows. Larger exposures occur within the Liwa area where low hills and mesas locally crop out within the interdune sabkhas between the megabarchan dunes.

\subsection{Quaternary alluvial fan deposits}

In the eastern Emirates, the extensive Quaternary alluvial fan deposits that extend out from the Hajar Mountains have been mapped as the Hili Formation. This is dominated by a cyclic succession of fining up conglomerate, sandstone and siltstone sequences over $50 \mathrm{~m}$ thick (Styles et al., 2006; Parton et al., 2015). Although derived from an ophiolitic hinterland, and dominated by harzburgite-rich gravels, the Hili Formation contains significant amounts of quartz sand. This is largely recycled from aeolian sand blown onto the alluvial fans and reworked by fluvial processes. Locally aeolian sandstones are preserved in the Hili Formation succession, particularly towards the distal margin where the alluvial fan merges with the Madinat Zayed Formation palaeodunes.

\section{Luminescence dating}

To provide a comprehensive representation of dune activity in this region, 93 samples for luminescence dating were taken from key localities across the UAE. Of these, 65 were collected by the BGS for the UAE Ministry of Energy and are documented in Farrant et al. (2012a). The additional 28 samples reported on here were collected later from key localities identified during the mapping work. All the samples were collected either as blocks of cemented sands and silts, or in opaque tubes filled with sediment. Samples were prepared and measured in the Aberystwyth Luminescence Research Laboratory. Cemented blocks of material had their outer surface removed by physical abrasion and were physically disaggregated, oven dried, and then milled to a fine powder prior to chemical analysis for dose rate determination. The innermost material that had not been exposed to light during sampling was prepared using standard techniques to obtain $180-211 \mu \mathrm{m}$ diameter quartz grains. Carbonates, gypsum and organic matter were removed using $\mathrm{HCl}$ and $\mathrm{H}_{2} \mathrm{O}_{2}$ respectively using up to 30 repeated washing cycles, and then dry sieved to obtain grains in the range $180-211 \mu \mathrm{m}$.

Quartz grains were then isolated using two cycles of density separation, one at 2.62 and one at 2.70 g.cm ${ }^{-3}$, and then etched in $40 \%$ hydrofluoric acid for 45 minutes and resieved.

\subsection{Dosimetry measurements}


Three analytical methods were used to collect data that could be used to calculate the external beta and gamma radiation dose from the decay of $\mathrm{K}$ and the members of the $\mathrm{U}$ and $\mathrm{Th}$ decay series from the surrounding sediment and from cosmic rays. A Geiger-mueller counter (Bøtter-Jensen and Mejdahl, 1988) was used to directly measure the emission of beta particles by the sample and the effective dose calculated by correcting for attenuation due to grain size and water content. ICP-MS and ICP-OES were used to obtain the $\mathrm{K}, \mathrm{U}$ and Th concentrations in the sediment and the gamma dose rate to the mineral grains was calculated using the conversion factors (from concentration to gamma dose rate) provided by Adamiec and Aitken (1998). The beta and gamma dose rates were then corrected for attenuation by water between the mineral grains. The cosmic dose rate was calculated using the equation provided by Prescott and Hutton (1994) with the burial depth obtained from field measurements. For all the samples considered here, the water content was taken as $3 \pm 2 \%$ (weight of water divided by weight of dry sediment). The dosimetry data for all samples is given in Table 2 . The final dose rate to be used in age calculation is the sum of the beta, gamma and cosmic dose rate and varied from 0.48 to $1.50 \mathrm{~Gy} / \mathrm{ka}$.

\subsection{Luminescence Measurements}

The equivalent dose $\left(D_{e}\right)$ was measured using the Single Aliquot Regenerative Dose (SAR) protocol (Wintle and Murray, 2000) using a Ris $\emptyset$ TL/OSL DA-15 reader. Preheat and cutheat temperatures of $220^{\circ} \mathrm{C}$ for 10 seconds and $160^{\circ} \mathrm{C}$ were used for all measurements. A dose recovery experiment was performed and the ratio of the given to the recovered dose was $0.96 \pm 0.02$ confirming that these parameters were appropriate for these samples. A number of replicate measurements of $D_{e}$ were made on each sample. Routinely, 24 medium-sized aliquots ( $5 \mathrm{~mm}$ diameter covered by grains, equating to ca.600 grains (Duller, 2008)) were measured and the data assessed by testing each aliquot against a number of criteria. Data were only accepted if they passed all of these acceptance criteria. The criteria applied were (1) recycling test, (2) IR OSL depletion ratio test (Duller, 2003), and (3) whether the signal obtained from the test dose exceeded three times the standard deviation of the background.

The quartz extracted from all the samples discussed here is very well suited to luminescence measurements. The quartz has a high OSL sensitivity, meaning that the magnitude of the OSL signal per unit radiation dose is high compared with other quartz samples. Additionally, the OSL signal is dominated by the fast OSL component (Wintle and Murray 2006) (Figure 6a and c). The suitability of the quartz for the SAR sequence can also be seen by the low number of aliquots that are rejected (see Table 2). The dose response curve, both for one of the younger samples (UAE7845; Figure 6b) and for one of the older samples (UAE7899; Figure 6e) are shown. In both cases the dose response has been fitted with the equation:

$$
\frac{L_{x}}{T_{x}}=I_{\operatorname{Max}}\left[1-e^{\frac{D}{D_{0}}}\right]
$$

where $L_{x} / T_{x}$ is the normalised luminescence signal measured in the SAR procedure in response to the radiation dose $\mathrm{D}, \mathrm{I}_{\mathrm{Max}}$ is the asymptotic value of the fitted curve, and $\mathrm{D}_{0}$ is the characteristic dose for the material and controls the rate at which the dose response curve approaches saturation.

Wintle and Murray (2006) suggested that if the $D_{e}$ was greater than twice the value of $D_{0}$ then the $D_{e}$ should be considered a minimum value. This view has been supported by recent work by Chapot et al (2012) who have shown that above the value suggested by Wintle and Murray (2006), quartz OSL ages underestimated the real age. In this study a conservative approach has been taken and any sample where the average $D_{e}$ has exceeded twice the average value of $D_{0}$ for the sample has been reported as a minimum age. In these cases the dose used to estimate the minimum age has been twice the value of 
$D_{0}$. Replicate $D_{e}$ values for both a young and old sample are shown in Figure 6 (c and f) showing good reproducibility in the data, as would be expected for well bleached samples in this region of high solar insolation. Where samples were not saturated, the final $\mathrm{D}_{\mathrm{e}}$ used for age calculation was calculated using the central age model (CAM).

\subsection{Comparison with other dates}

The 93 samples dated by BGS were combined with 282 existing published and unpublished OSL analyses (Table 1, Figures 3 and 4) from the northern upwind margin of the Rub' al Khali. Age determinations from publications without adequate stratigraphical context or location details were excluded. This larger dataset was analysed using a cumulative probability frequency method. Only finite dates with resolvable uncertainties were included in this analysis; 28 samples tending to saturation were excluded. The method provides a rigorous treatment of the errors associated with each age estimate by modelling the probable normal distribution of the true age about the quoted age and error values. Thus analyses with small uncertainties are represented by a normal distribution peak with a low dispersion, while those with high uncertainties have a much broader, shallower peak. We employed an interval of 250 years to calculate the normal distribution probability curves for each sample. The cumulative frequencies for multiple samples, grouped according to formation or dune type, were then calculated by summing the respective probabilities for each group of analyses and normalised to produce the final frequency curve. Consequently, the results do not give any significance to the relative peak magnitude and do not reflect the intensity or otherwise of any climatic event. The selection of a 250 year interval enables the potential recognition of short-term events and enables a smooth curve to be generated.

\section{Results and discussion}

\subsection{Luminescence results}

The results of the OSL dating programme from this study are shown in Table 2 and presented in more detail in the supplementary data online. The data from Farrant et al. (2012a) are also reproduced here.

\subsection{Comparison with other dates}

All the OSL dates used in this study are shown in Figure 7, grouped by author and by lithology or dune form. The cumulative probability frequency curves derived from analysing these 334 existing published and unpublished OSL analyses are shown in Figure 8. However, these curves should be interpreted with caution (Chiverrell et al., 2011) as they are affected by sampling, age and geographical bias. For any individual dune there will be a spread of OSL ages depending on depth of each sample. The magnitude of this spread reflects the dune reconstitution time, although for small, actively migrating dunes, this is likely to be quite short. The minor peaks in the dune sand cumulative probability curve at c. 20-21 ka and at 14-15 ka (Figure 8) are derived from basal ages from some of the larger accretionary dune forms along the eastern margin of the dune field around Ash Shiweb and Ras al Khaimah (Atkinson et al., 2011; Leighton et al., 2014). These reflect a dune reconstitution time lag of up to c. $10 \mathrm{ka}$ between initial accretion and in-situ stabilisation. In addition, beyond $\sim 130 \mathrm{ka}$ the small number of finite samples precludes obtaining meaningful distributed error frequency curves. Similarly, the small number of Hili Formation (aeolian) samples means that this curve in particular may not show all periods of dune accretion; in particular the record prior to MIS 4 should be treated with caution. In addition, sampling bias, where multiple samples are taken from a single dune or core can also affect the result, notably for the data from Stokes and Bray (2005) and Leighton et al. (2013).

However, it is clear both from the spread of actual dates (Figure 7) and the frequency curves that at least three and possibly six significant periods of dune formation and stabilisation can be recognised. 
The oldest of these occurred during Marine Isotope Stage (MIS) 5e (c. 120-130 ka), with other periods during MIS 5c (c. 100-110 ka), and 5a (73-83 ka), around the MIS 3-4 boundary (c. 50-57 ka), and with the most recent occurring at c. 9.5-11 ka and during the late Holocene-present. The peaks in dune formation that can be resolved from this data set are correlated with the Indian Ocean monsoon record of Leuschner and Sirocko (2003), indicating that dune preservation is linked to higher rainfall driven by monsoonal incursions. However, uncertainties in the data mean the timing and duration of periods of dune stabilisation earlier than MIS 5a should be treated with caution. Whilst the frequency plots suggest that periods of dune stabilisation occurred prior to this time, and are linked with monsoonal incursions, the record is not sufficiently complete or precise to be confident in the timing and duration of these humid interludes. Earlier phases of dune activity beyond MIS5e are clearly evident from the geological record, but the chronology is either too imprecise with large errors or beyond the range of the OSL dating method.

The earliest possible phase of dune activity is represented by the Madinat Zayed Formation. This forms an extensive and largely unrecognised paleoerg across much of the central UAE, deposited as a southward migrating dune-field whose age has been partially determined by OSL dating (Stokes and Bray 2005; Farrant et al., 2012a). The majority of the finite dates occur within MIS 5 with particular clusters showing as peaks around 50, 70-75, 100-110 and $120 \mathrm{ka}$ (Figure 8). Dates extending back to c. $137 \mathrm{ka}$ were obtained by Stokes and Bray (2005) from both core boreholes and interdune outcrops of the Madinat Zayed Formation in the Al Qafa region north of the Liwa oasis, and to c. 209 ka (MIS 7) from a cored borehole in the Liwa area. Similar ages were obtained by Wood et al., (2003). However, the error bars on the finite dates from this formation are significant and coupled with uncertainties due to dune reconstitution times preclude defining periods of dune accumulation beyond c. $160 \mathrm{ka}$. Moreover, many samples were saturated and beyond the range of the technique. Given the known thickness of the deposit (locally $>50 \mathrm{~m}$ ) and the depth of erosion, most of the formation is likely to significantly pre-date MIS 5. Sedimentary evidence from quarries around Madinat Zayed indicates multiple horizons with fresh or brackish water playa lake sediments and stabilised dunes with distinct rooted palaeosols (Newell, et al., 2012). Unfortunately all these sites are beyond the current range of OSL dating but the formation clearly records a highly variable climatic period spanning >MIS 6-5 with both dune accumulation and fluvial-humid interludes. A similar picture is also shown in the Wahiba Sands, Oman, where dune sands interspersed with palaeosols were observed (Radies et al., 2004; Preusser et al., 2002; Presusser, 2009). Many of the finite aeolian Madinat Zayed formation OSL dates are coeval (within error) of alluvial fan gravel deposits from the $\mathrm{Al}$ Ain area (Parton et al., 2015) suggesting dune stabilisation in the basin is synonymous with alluvial fan aggregation in the mountains.

The Ghayathi Formation carbonate dunes are very sensitive palaeoclimate indicators due to short dune reconstitution times and rapid cementation rates. The dating substantiates evidence from exposed sections that the formation consists of more than one generation of aeolian deposits (Figure 5). The earliest carbonate dunes, dated to MIS 5e, occur around Dubai and Abu Dhabi, followed by a second generation of barchan dunes which were deposited along the Gulf coast between c. 70-80 ka (MIS 5a). These two periods of dune formation do not appear as clear peaks in Figure 8 due to the small number of dates and large error bars. A third cluster of dates from late MIS 4 (c. 54-62 ka), which appears as a low, broad peak in Figure 8, suggests a period of dune cementation at this time, indicative of a brief wet phase which is coeval with the alluvial fan record of Parton et al., (2013). This peak is also recorded by the Madinat Zayed Formation and aeolian sands preserved within the Hili Formation (Figure 8). Similarly, the marked cluster of dates around the Late PleistoceneHolocene transition clearly indicates a significant period of dune stabilisation at the start of the early Holocene wet period (10 ka). This is the most extensive phase of carbonate dune stabilisation in the 
Emirates, extending across much of the region between Abu Dhabi and Dubai. These dates also indicate that the younger Ghayathi Formation palaeodune ridges around Dubai are coeval with the unconsolidated dune ridges further east around Ras al Khaimah and Ash Shiweb (Atkinson et al., 2011). This demonstrates that the deposition of the Ghayathi Formation does not represent a distinct, localised period of carbonate deposition, but rather there is a north-eastward (downwind) change to a more siliciclastic lithology as the carbonate content is diluted downwind. The degree of cementation cannot be used as a guide to the age of a dune.

The lack of OSL dates between c. 70-30 ka is noteworthy. The absence of aeolian OSL dates from this period does not, as some suggest (Preusser, 2009) reflect the cutting off of the sediment supply following the stabilisation of the Persian Gulf basin. Rather it is the low preservation potential of actively migrating transverse and barchan dune forms in an arid climate due to extensive dune recycling. Sea-level change would do relatively little to change the amount of sediment in transport as much of the quartz sand currently in the modern Rub' al-Khali is derived from the deflation of the thick Miocene and palaeodune deposits along the Gulf coast. Only the carbonate sands and the Ghayathi Formation, which volumetrically are a relatively minor component of the dune system, are derived from the Gulf basin. Instead climatic effects, including changes in groundwater level and vegetation growth are the predominant controls for the rate of deflation and sediment supply.

Most fluvial activity in the UAE ceased around $70 \mathrm{ka}$, marking a major period of aridity during MIS 2-4 apart from the brief humid interlude at the end of MIS 4 (ca. 61-58 ka) (Parton et al., 2013, 2015). During this period, the dune field migrated south and east, transgressing over the inactive alluvial fans along the margins of the Hajar Mountains. Most of the large-scale, unconsolidated dune forms including the major dune ridges around Ras al Khaimah accumulated between 20-10 ka at the end of this arid phase, before being stabilised at the onset of the early Holocene wet period at $10 \mathrm{ka}$ (Parker et al., 2004; 2006). These dune forms have continued to develop as the climate turned increasingly arid over the last c. $6 \mathrm{ka}$. The multiple spikes in Figure 8 during the latter part of the Holocene reflect variable dune reconstitution times due to active dune migration which continues to the present day, locally exacerbated by human activities (Goudie et al., 2000; Parker and Goudie, 2008; Atkinson et al., 2013).

\section{Conclusions}

Geological mapping combined with targeted OSL dating of key sections in the UAE has yielded new insights into the chronostratigraphy of dunes in the northern Rub' al-Khali. In addition to Late Pleistocene and Holocene unconsolidated dunes, two palaeodune sequences have been identified; the carbonate dominated Ghayathi Formation and the older siliciclastic Madinat Zayed Formation. The OSL dates clearly imply that the aeolian record is preservation limited, recording dune stabilisation and cementation at the onset of humid episodes. These are linked with periods of monsoonal incursion during MIS 5e, 5c and 5a, at the end of MIS 4/early MIS 3, and during the Early Holocene. The lack of OSL dates suggest periods of aridity at various intervals, notably during most of MIS 2-4 and at intervals during MIS 5. However, the record of dune stabilisation during MIS 5 and earlier is ambiguous, mainly due to the low precision of the OSL dates and uncertainties due to dune reconstitution times. The record pre- MIS 5a is imprecise, but protracted periods of aridity appear unlikely from geological evidence. It is anticipated that the preservation of the Madinat Zayed Formation palaeodunes probably occurred during humid episodes linked to insolation peaks during MIS 6-7 and earlier.

\section{References}

Adamiec, G., Aitken, M.J., 1998. Dose-rate conversion factors: update. Ancient TL 16, 37-50. 
Allen, J.R.L. 1974. Reaction, relaxation and lag in natural sedimentary systems: general principles, examples and lessons. Earth Science Reviews 10, 263-342.

Armitage, S. J., Jasim, S. A., Marks, A. E., Parker, A. G., Usik, V. I., Uerpmann, H. P. 2011. The southern route out of Africa: evidence for an early expansion of modern humans into Arabia. Science $331,453-456$.

Atkinson, O.A., Thomas, D.S., Goudie, A.S., Bailey, R.M., 2011. Late Quaternary chronology of major dune ridge development in the northeast Rub'al-Khali, United Arab Emirates. Quaternary Research 76, 93-105.

Atkinson, O.A., Thomas, D.S., Goudie, A.S., Parker, A.G., 2012. Holocene development of multiple dune generations in the northeast Rub'al-Khali, United Arab Emirates. The Holocene 22, 179-189.

Atkinson, O.A., Thomas, D.S., Parker, A.G., Goudie, A.S., 2013. Late Quaternary humidity and aridity dynamics in the northeast Rub'al-Khali, United Arab Emirates: Implications for early human dispersal and occupation of eastern Arabia. Quaternary International 300, 292-301.

Barth, H. J. 2001. Characteristics of the wind regime north of Jubail, Saudi Arabia, based on high resolution wind data. Journal of Arid Environments 47, 387-402.

Bray, H.E., Stokes, S., 2003. Chronologies for Late Quaternary barchan dune reactivation in the southeastern Arabian Peninsula. Quaternary Science Reviews 22, 1027-1033.

Bray, H.E., Stokes, S., 2004. Temporal patterns of arid-humid transitions in the south-eastern Arabian Peninsula based on optical dating. Geomorphology 59, 271-280.

Burns, S.J., Fleitmann, D., Matter, A., Neff, U., Mangini, A., 2001. Speleothem evidence from Oman for continental pluvial events during interglacial periods. Geology 29, 623-626.

Chapot, M.S., Roberts, H.M., Duller, G.A.T., Lai, Z.P., 2012. A comparison of natural- and laboratory-generated dose response curves for quartz optically stimulated luminescence signals from Chinese loess. Radiation Measurements 47, 1045-1052.

Chase, B., 2009. Evaluating the use of dune sediments as a proxy for palaeo-aridity: a southern African case study. Earth-Science Reviews 93, 31-45.

Chiverrell, R.C., Thorndycraft, V.R., Hoffmann, T.O., 2011. Cumulative probability functions and their role in evaluating the chronology of geomorphological events during the Holocene. Journal of Quaternary Science 26, 76-85.

Crassard, R., Petraglia, M.D., Drake, N.A., Breeze, P., Gratuze, B., Alsharekh, A., Arbach, M., Groucutt, H.S., Khalidi, L., Michelsen, N., Robin, C.J., Schiettecatte, J., 2013. Middle Palaeolithic and Neolithic occupations around Mundafan palaeolake, Saudi Arabia: implications for climate change and human dispersals. PloS one 8, e69665.

Cuttler, R., Beech, M., Zander, A., Kallweit, H., Al-Tikriti, W., 2007. Nomadic Communities of the Holocene Climatic Optimum: Excavation and research at Kharimat Khor al Manahil and Khor Al Manahil in the Rub' al-Khālī, Abu Dhabi, UAE. Proceedings of the Seminar for Arabian Studies 37, 61-78.

Duller, G.A.T., 2003. Distinguishing quartz and feldspar in single grain luminescence measurements. Radiation Measurements 37, 161-165.

Duller, G.A.T., 2004. Luminescence dating of Quaternary sediments: recent advances. Journal of Quaternary Science 19, 183-192. 
Duller, G.A.T., 2008. Single grain optical dating of Quaternary sediments: why aliquot size matters in luminescence dating. Boreas 37, 589-612.

Edgell, H.S., 2006. Arabian deserts, Nature, Origin and Evolution. Springer, Dordecht.

Embabi, N.S., El-Sharkawy, F.M., 1989. Landform systems of the United Arab Emirates from space images. 1st Symposium on Remote Sensing, UAE University, Al-Ain, 7-28.

Evans, G., 2011. An historical review of the Quaternary sedimentology of the Gulf (Arabian/Persian Gulf) and its geological impact, in: Kendall, C.G.S., Alshahran, A.S. (Eds.), Quaternary carbonate and evaporite sedimentary facies and their ancient analogues. A tribute to Douglas James Shearman. Special Publication Number 43 of the International Association of Sedimentologists. WileyBlackwell.

Farrant, A.R., Ellison, R.A., Thomas, R.J., Pharaoh, T.C., Newell, A.J., Goodenough, K.M., Lee, J.R., Knox, R.O.B., 2012a. The Geology and Geophysics of the United Arab Emirates. Volume 6: Geology of the western and central United Arab Emirates. British Geological Survey, Keyworth, Nottingham.

Farrant, A R., Ellison, R.A, Leslie, A., Finlayson, A., Thomas, R.J, Lee, J.R, Burke, H., Price, S.J, Merritt, J.W., Merritt, J., 2012b. Geology of the Al Wathba 1: 100000 map sheet, 100-12, United Arab Emirates. British Geological Survey, Keyworth, Nottingham.

Farrant, A R., Price, S. J, Arkley, S., Finlayson, A., Thomas, R.J., Leslie, A., 2012c. Geology of the Al Lisaili 1: 100000 map sheet, 100-6, United Arab Emirates. British Geological Survey, Keyworth, Nottingham.

Farrant, A.R., Ellison, R.A., 2014. Sand, Sea, Sunshine and Sabkhas; the Quaternary story of the desert and the Arabian Gulf coast, in: Thomas, R.J., Ellison, R.A. (Eds.), Geological Evolution of the United Arab Emirates. Over six hundred million years of Earth history. British Geological Survey, Keyworth, Nottingham.

Fleitmann, D., Burns, S.J., Mangini, A., Mudelsee, M., Kramers, J., Villa, I., Ulrich Neff, U., AlSubbary, A.A., Buettner, A., Hippler, D., Matter, A., 2007. Holocene ITCZ and Indian monsoon dynamics recorded in stalagmites from Oman and Yemen (Socotra). Quaternary Science Reviews 26, 170-188.

Fleitmann, D., Matter, A., 2009. The speleothem record of climate variability in Southern Arabia. Comptes Rendus Geoscience 341, 633-642.

Glennie, K.W., Singhvi, A.K., 2002. Event stratigraphy, paleoenvironment and chronology of SE Arabian deserts. Quaternary Science Reviews 21, 853-869.

Goudie, A.S., Colls, A., Stokes, S., Parker, A., White, K., Al-Farraj, A., 2000. Latest Pleistocene and Holocene dune construction at the north-eastern edge of the Rub' al-Khali, United Arab Emirates. Sedimentology 47, 1011-1021.

Groucutt, H.S., Petraglia, M.D., 2012. The prehistory of the Arabian peninsula: deserts, dispersals, and demography. Evolutionary Anthropology: Issues, News, and Reviews 21, 113-125.

Hussain, M. 2006. Recognizing attributes and oomoldic porosity development in eolianite in an arid setting: An example from the quaternary eolianite from the Arabian Gulf coastline, Saudi Arabia. Carbonates and Evaporites 21, 124-132.

Lancaster, N. 2008. Desert dune dynamics and development: insights from luminescence dating. Boreas 37, 559-573. 
Leighton, C.L., Bailey, R.M., Thomas, D.S., 2013. The utility of desert sand dunes as Quaternary chronostratigraphic archives: evidence from the northeast Rub' al Khali. Quaternary Science Reviews 78, 303-318.

Leighton, C.L., Thomas, D.S., Bailey, R.M., 2014. Reproducibility and utility of dune luminescence chronologies. Earth-Science Reviews 129, 24-39.

Leuschner, D.C., Sirocko, F., 2003. Orbital insolation forcing of the Indian Monsoon-a motor for global climate changes? Palaeogeography, Palaeoclimatology, Palaeoecology 197, 83-95.

Lacinska, A.M., Styles, M.T., Farrant, A.R., 2014. Near-surface diagenesis of ophiolite-derived conglomerates of the Barzaman Formation, United Arab Emirates: a natural analogue for permanent $\mathrm{CO} 2$ sequestration via mineral carbonation of ultramafic rocks. Geological Society, London, Special Publications 392, 343-360.

Murray, A.S., Wintle, A.G., 2000. Luminescence dating of quartz using an improved single-aliquot regenerative-dose protocol. Radiation measurements 32, 57-73.

Newell, A.J., Farrant, A.R., Lee, J.R., Smith, R.A., Burke, H.F., Thomas, R.J., Ellison, R.A., 2012. Geology of the Madinat Zayed 1:100 000 map sheet, 100-21, United Arab Emirates. British Geological Survey, Keyworth, Nottingham.

Parker, A.G., 2010. Pleistocene climate change from Arabia - developing a framework for hominin dispersal over the last 350 kyr, in: Petraglia, M.D, and Rose, J., (Eds), The Evolution of Human Populations in Arabia. Vertebrate Paleobiology and Paleoanthropology. Dordrecht: Springer Science $39-49$.

Parker, A. G., Eckersley, L., Smith, M. M., Goudie, A. S., Stokes, S., Ward, S., White, K.W., Hodson, M. J., 2004. Holocene vegetation dynamics in the northeastern Rub' al-Khali desert, Arabian Peninsula: a phytolith, pollen and carbon isotope study. Journal of Quaternary Science 19, 665-676.

Parker, A. G., Goudie, A. S., Stokes, S., White, K., Hodson, M. J., Manning, M., Kennet, D., 2006. A record of Holocene climate change from lake geochemical analyses in southeastern Arabia. Quaternary Research 66, 465-476.

Parker, A.G., Goudie, A.S., 2007. Development of the Bronze Age landscape in the southeastern Arabian Gulf: new evidence from a buried shell midden in the eastern extremity of the Rub' al Khali desert, Emirate of Ras al Khaimah, UAE. Arabian Archaeology and Epigraphy 18, 132-138.

Parker, A.G., Goudie, A.S., 2008. Geomorphological and palaeoenvironmental investigations in the southeastern Arabian Gulf region and the implication for the archaeology of the region. Geomorphology 101, 458-470.

Parton, A., 2013. Late Pleistocene climate change in southeast Arabia; implications for human migration and dispersal. Unpublished $\mathrm{PhD}$ thesis, Oxford Brookes University.

Parton, A., Farrant, A.R., Leng, M.J., Schwenninger, J.L., Rose, J.I., Uerpmann, H.P., Parker, A.G. 2013. An early MIS 3 pluvial phase in Southeast Arabia: Climatic and archaeological implications. Quaternary International 300, 62-74.

Parton, A., White, T.S., Parker, A.G., Breeze, P.S., Jennings, R.J., Groucutt, H.S., Petraglia, M.D., 2015. Orbital-scale climate variability in Arabia as a potential motor for human dispersals. Quaternary International, (in press, this issue) 
Parton, A., Parker, A.G., Farrant, A. R., Leng, M.J., Telfer, M.W., Groucutt, H.S., Petraglia, M.D. 2015. Alluvial fan records from southeast Arabia reveal multiple windows for human dispersal. Geology (accepted in press), DOI: 10.1130/G36401.1

Prescott, J.R., Hutton, J.T., 1994. Cosmic ray contributions to dose rates for luminescence and ESR dating: large depths and long-term time variations. Radiation Measurements 23, 497-500.

Preusser, F., 2009. Chronology of the impact of Quaternary climate change on continental environments in the Arabian Peninsula. Comptes Rendus Geoscience 341, 621-632.

Preusser, F., Radies, D., Matter, A., 2002. A 160,000-year record of dune development and atmospheric circulation in Southern Arabia. Science 296 (5575), 2018-2020

Radies, D., Preusser, F., Matter, A., \& Mange, M., 2004. Eustatic and climatic controls on the development of the Wahiba Sand Sea, Sultanate of Oman. Sedimentology 51, 1359-1385.

Rosenberg, T.M., Preusser, F., Blechschmidt, I., Fleitmann, D., Jagher, R., Matter, A., 2012. Late Pleistocene palaeolake in the interior of Oman: a potential key area for the dispersal of anatomically modern humans out-of-Africa? Journal of Quaternary Science 27, 13-16.

Rosenberg, T.M., Preusser, F., Fleitmann, D., Schwalb, A., Penkman, K., Schmid, T.W., Al-Shanti, M.A., Kadi, K., Matter, A., 2011. Humid periods in southern Arabia: windows of opportunity for modern human dispersal. Geology 39, 1115-1118.

Rosenberg, T.M., Preusser, F., Risberg, J., Plikk, A., Kadi, K.A., Matter, A., Fleitmann, D., 2013. Middle and Late Pleistocene humid periods recorded in palaeolake deposits of the Nafud desert, Saudi Arabia. Quaternary Science Reviews 70, 109-123.

Stokes, S., Bray, H.E., 2005. Late Pleistocene eolian history of the Liwa region, Arabian Peninsula. Geological Society of America Bulletin 117, 1466-1480.

Stone, A. E. C., Thomas, D. S. G., 2013. Casting new light on late Quaternary environmental and palaeohydrological change in the Namib Desert: A review of the application of optically stimulated luminescence in the region. Journal of Arid Environments 93, 40-58.

Styles, M., Ellison, R., Arkley, S., Crowley, Q.G., Farrant, A., Goodenough, K.M., McKervey, J., Pharaoh, T., Phillips, E., Schofield, D., Thomas, R.J., 2006. The geology and geophysics of the United Arab Emirates: Volume 1, Geology. British Geological Survey, Keyworth, Nottingham.

Thomas, D. S., Burrough, S. L. 2012. Interpreting geoproxies of late Quaternary climate change in African drylands: Implications for understanding environmental change and early human behaviour. Quaternary International 253, 5-17.

White, K., Goudie, A., Parker, A., Al-Farraj, A. 2001. Mapping the geochemistry of the northern Rub' al-Khali using multispectral remote sensing techniques. Earth Surface Processes and Landforms 26, 735-748

Wintle, A.G., Murray, A.S., 2006. A review of quartz optically stimulated luminescence characteristics and their relevance in single-aliquot regeneration dating protocols. Radiation Measurements 41, 369-391.

Wood, W.W., Rizk, Z.S., Alsharhan, A.S., 2003. Timing of recharge, and the origin, evolution and distribution of solutes in a hyperarid aquifer system. Developments in Water Science 50, 295-312. 
Zander, A., Degering, D., Preusser, F., Kasper, H.U., Brückner, H., 2007. Optically stimulated luminescence dating of sublittoral and intertidal sediments from Dubai, UAE: Radioactive disequilibria in the uranium decay series. Quaternary Geochronology 2, 123-128.

\section{Acknowledgements}

The OSL ages were determined at Aberystwyth University with the assistance of Hollie Wynne. Farrant, Bide and Knox publish with the approval of the Executive Director of the British Geological Survey. This paper is dedicated to the late Robert Knox.

\section{Figures}

Figure 1. Location of the Rub' al Khali dunefield and present day wind patterns.

Figure 2. Schematic cross-section through the Quaternary deposits in the northern Rub' al-Khali, showing generalised stratigraphic relationships. For more details, see Farrant et al. (2012a), and Farrant and Ellison (2014).

Figure 3 Location of OSL sample sites by author. Samples collected by the British Geological Survey include those in this study, Farrant et al. (2012a) and Parton (2013). For more accurate locations, refer to the original publications and Table 2 .

Figure 4 Location of OSL sample sites grouped by lithology. The approximate extent of the two palaeodune formations and the Hili Formation are shown, and are based on Farrant et al. (2012a).

Figure 5. A. Excavation in the Ghayathi Formation near Baniyas, Abu Dhabi [UTM 40266367 2693793], showing two phases of Ghayathi Formation palaeodune deposition dated to $116 \pm 8.4 \mathrm{ka}$ (sample UAE 6915) and at 10.0 $\pm 0.7 \mathrm{ka}$ (sample UAE 6916). B. Section near Mafaq, Abu Dhabi [UTM 40253970 2685972] showing well cemented Ghayathi Formation calcarenite overlying unconsolidated quartzose sand dated to $22.7 \pm 1.8 \mathrm{ka}$ (sample UAE 6921). Both figures are from Farrant (2012a).

Figure 6: Luminescence data for one of the younger samples reported here UAE 7845 (a-c) and one of the older samples, UAE 7899 (d-f). Typical decay curves are shown for each sample (a and d), along with dose response curves ( $b$ and e) and radial plots of calculated $D_{e}$ values (c and f).

Figure 7. OSL ages grouped by author and lithology. A more detailed discussion of the dune ages during the Holocene can be found in Leighton et al. (2014).

Figure 8. Cumulative probability distribution frequency curve results for each lithological group. The data is normalised, so the magnitude of the peak does not reflect the intensity of the event. The top line is Indian Ocean Monsoon Index (Leuschner and Sirocko, 2003). Shaded bars represent most likely periods of dune stabilisation which can be correlated with humid periods in the Indian Ocean Monsoon Index.

Table 1. Published OSL ages used in this study. Only sources where the location and stratigraphy could be determined were analysed. Six lithological groups have been identified: Dune sand (any unconsolidated aeolian sand with the exception of the Liwa megabarchans); Megabarchans; Ghayathi Formation, Madinat Zayed Formation, and the Hili Formation. The latter can be split into an aeolian and a fluvial component.

Table 2. A. OSL data for samples collected during this study. Grid references are in UTM Format, Zone 40, WGS84. The number of aliquots indicates the number of aliquots that passed all the acceptance criteria described in the text and which yielded De values used in age calculation. The figures in parentheses are the total number of aliquots measured. Sample metadata is available in the 
supplementary data. B. OSL data for samples collected during the BGS Mapping project for the UAE Ministry of Energy. Data from Farrant et al. (2012a). Grid references are in UTM Format, Zone 40, WGS84 with the exception of UAE 7344 and UAE 7346 (Sabkha Mati - marked with *) which are in UTM Format, Zone 39, WGS84. Sample metadata is available in Farrant et al. (2012a).

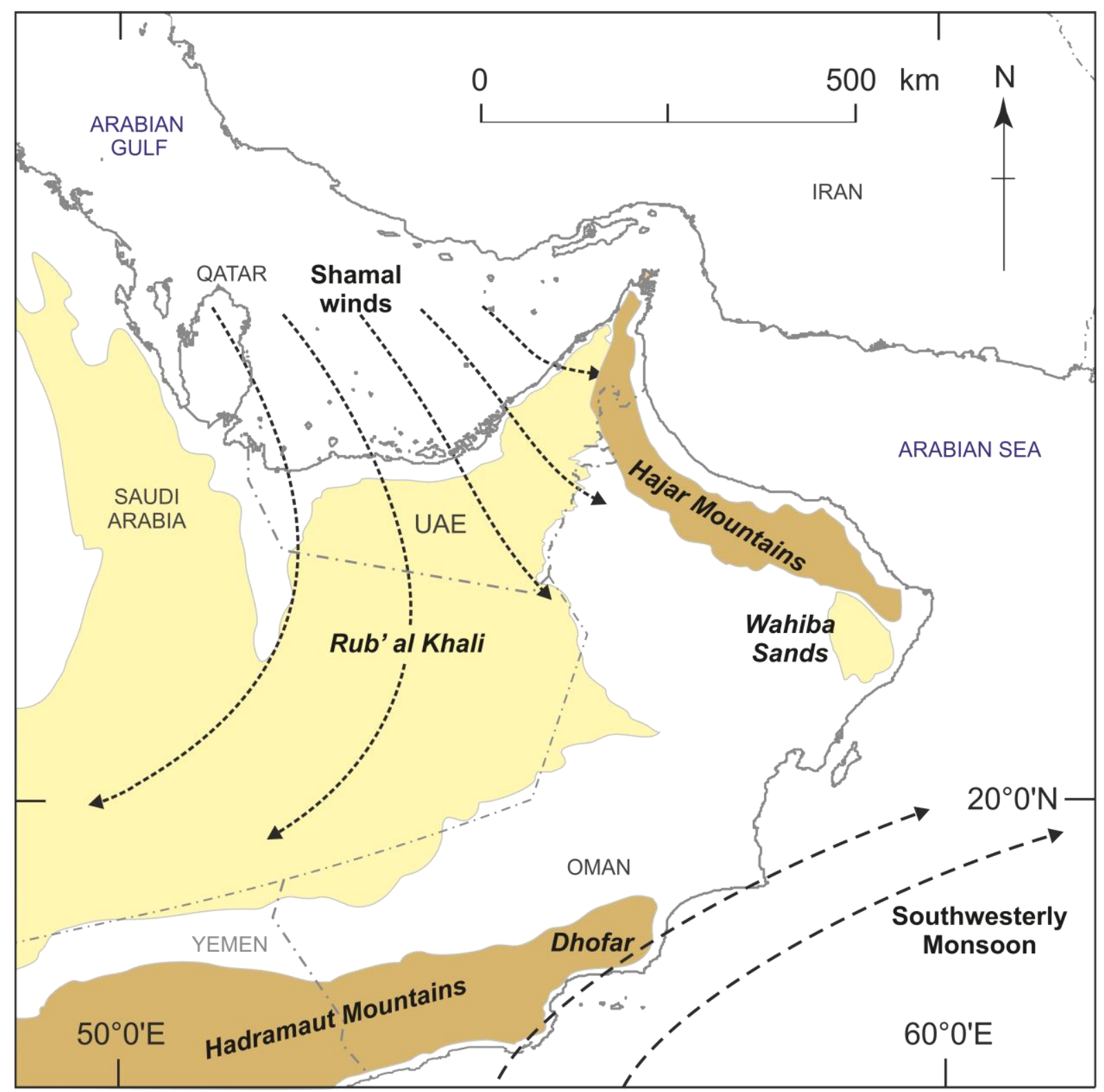

Figure 1. Location of the Rub' al Khali dunefield and present day wind patterns. 


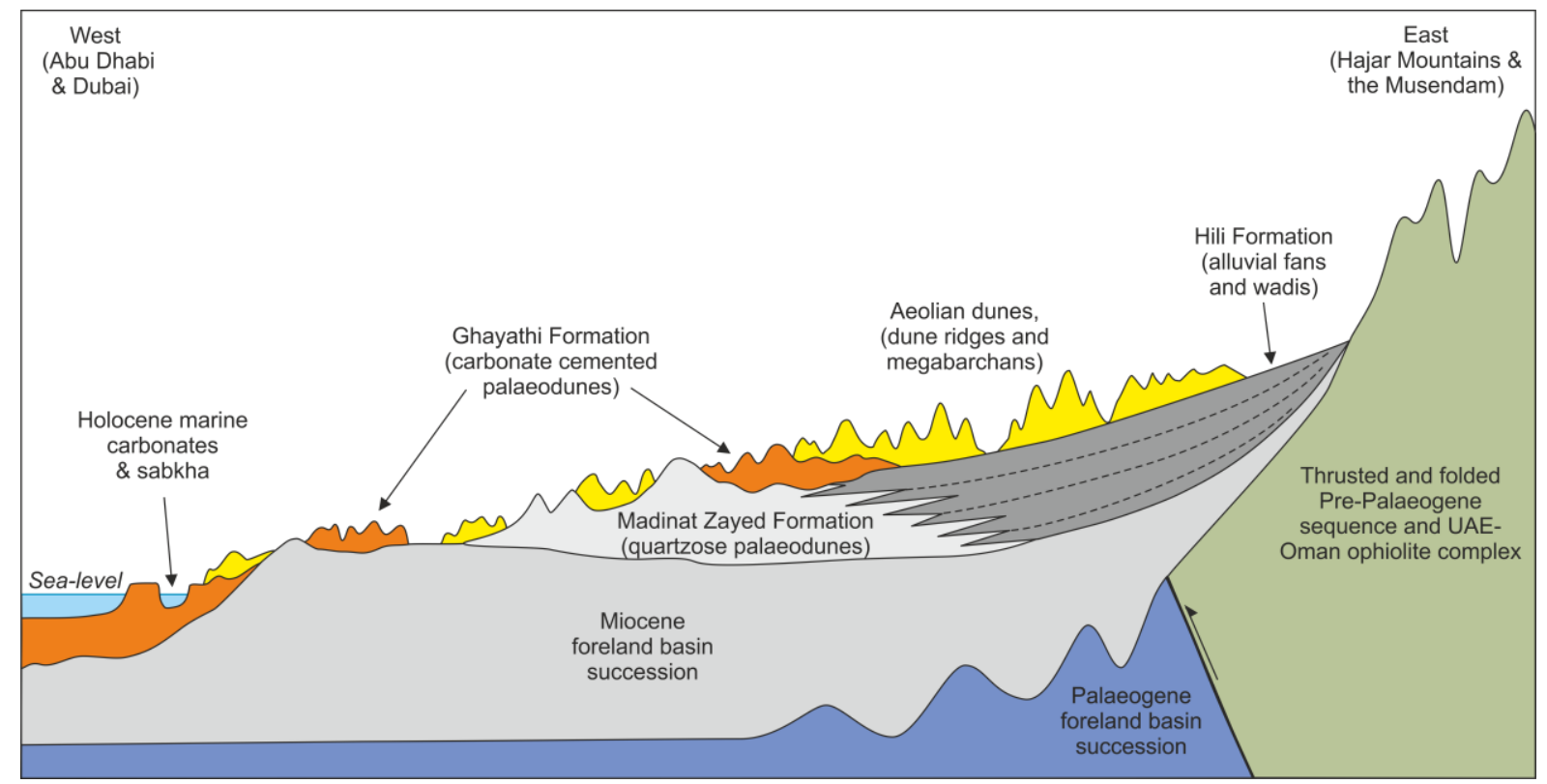

Figure 2. Schematic cross-section through the Quaternary deposits in the northern Rub' al-Khali, showing generalised stratigraphic relationships. For more details, see Farrant et al. (2012a), and Farrant and Ellison (2014).

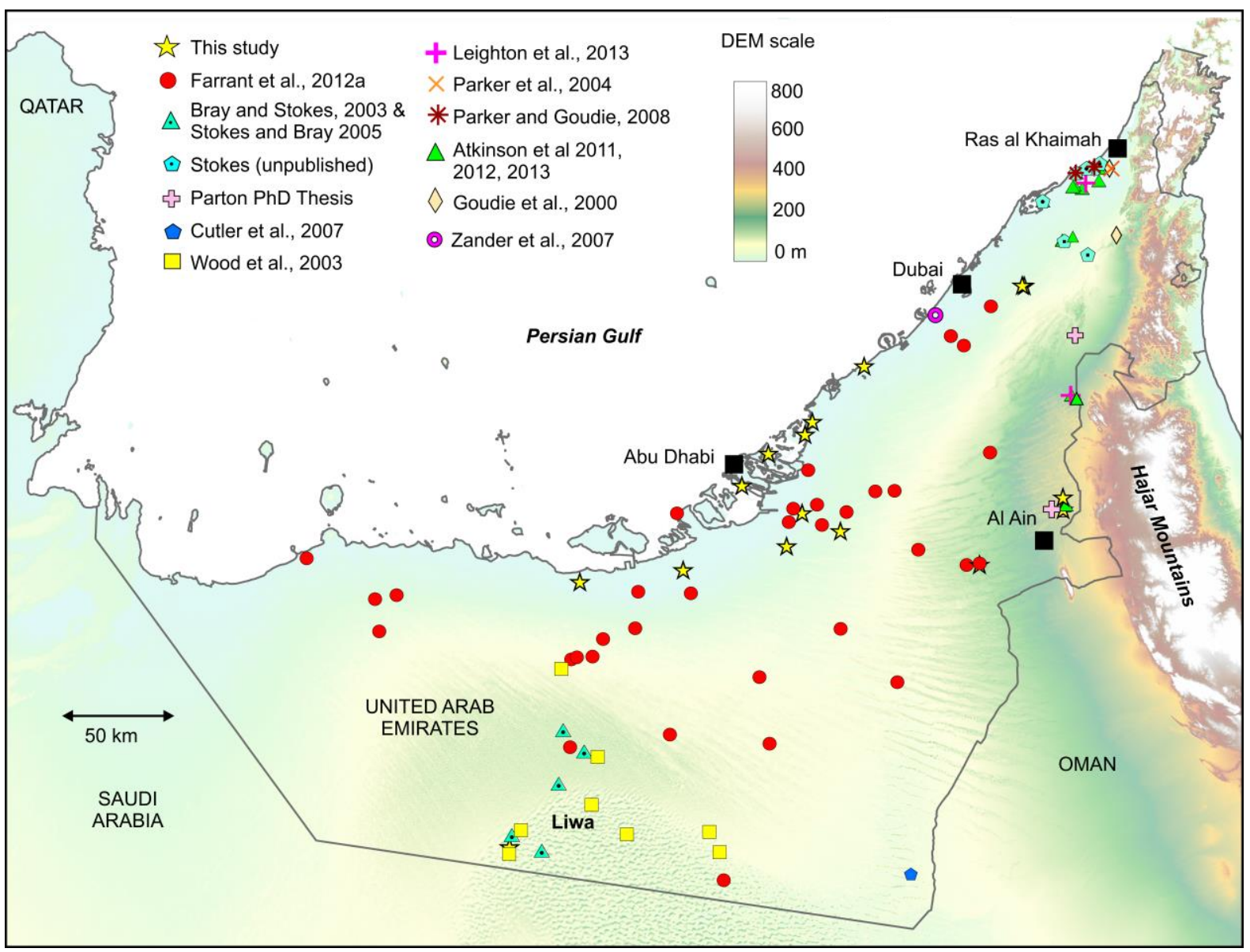

Figure 3 Location of OSL sample sites by author. Samples collected by the British Geological Survey include those in this study, Farrant et al. (2012a) and Parton (2013). For more accurate locations, refer to the original publications and Table 2. 


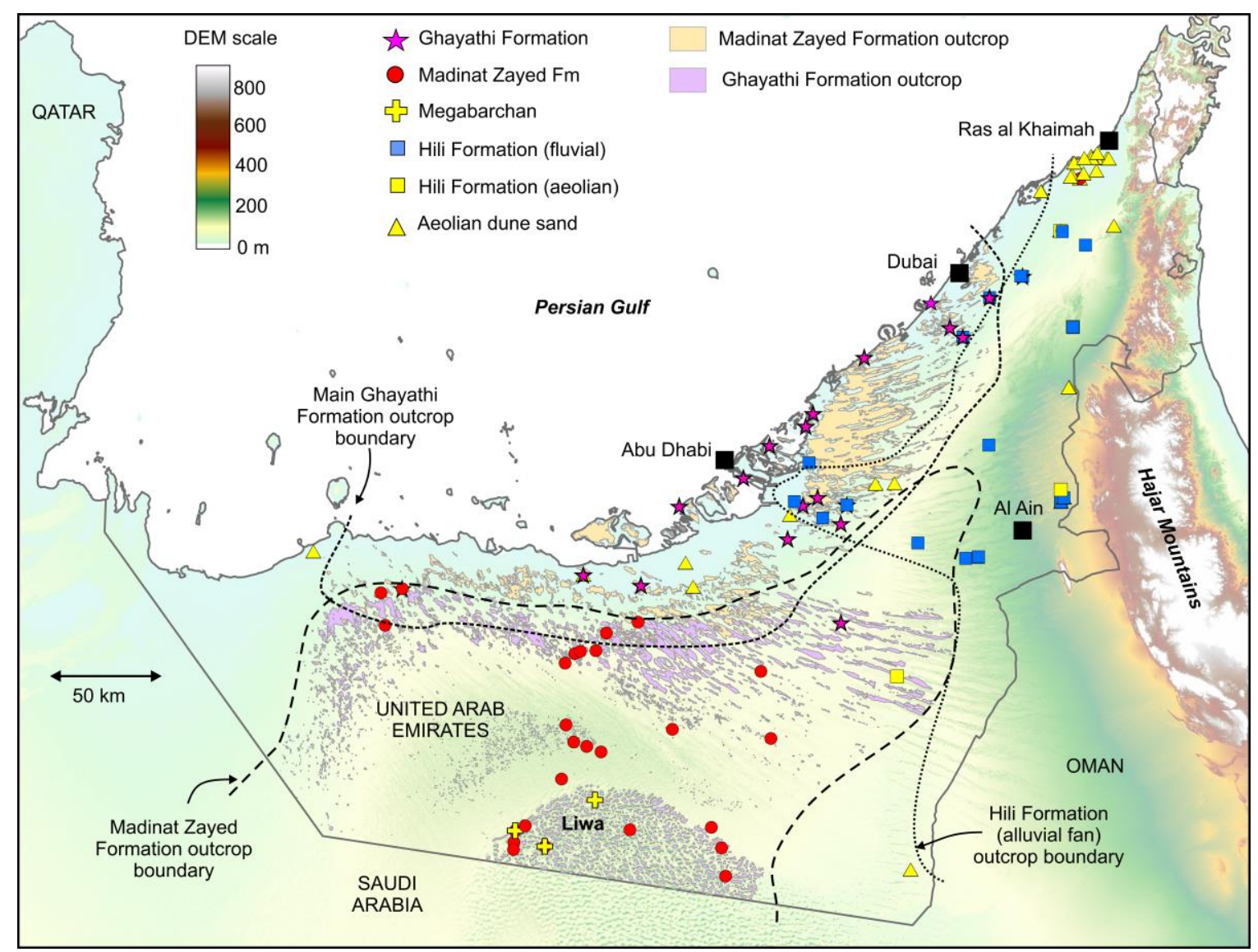

Figure 4 Location of OSL sample sites grouped by lithology. The approximate extent of the two palaeodune formations and the Hili Formation are shown, and are based on Farrant et al. (2012a).
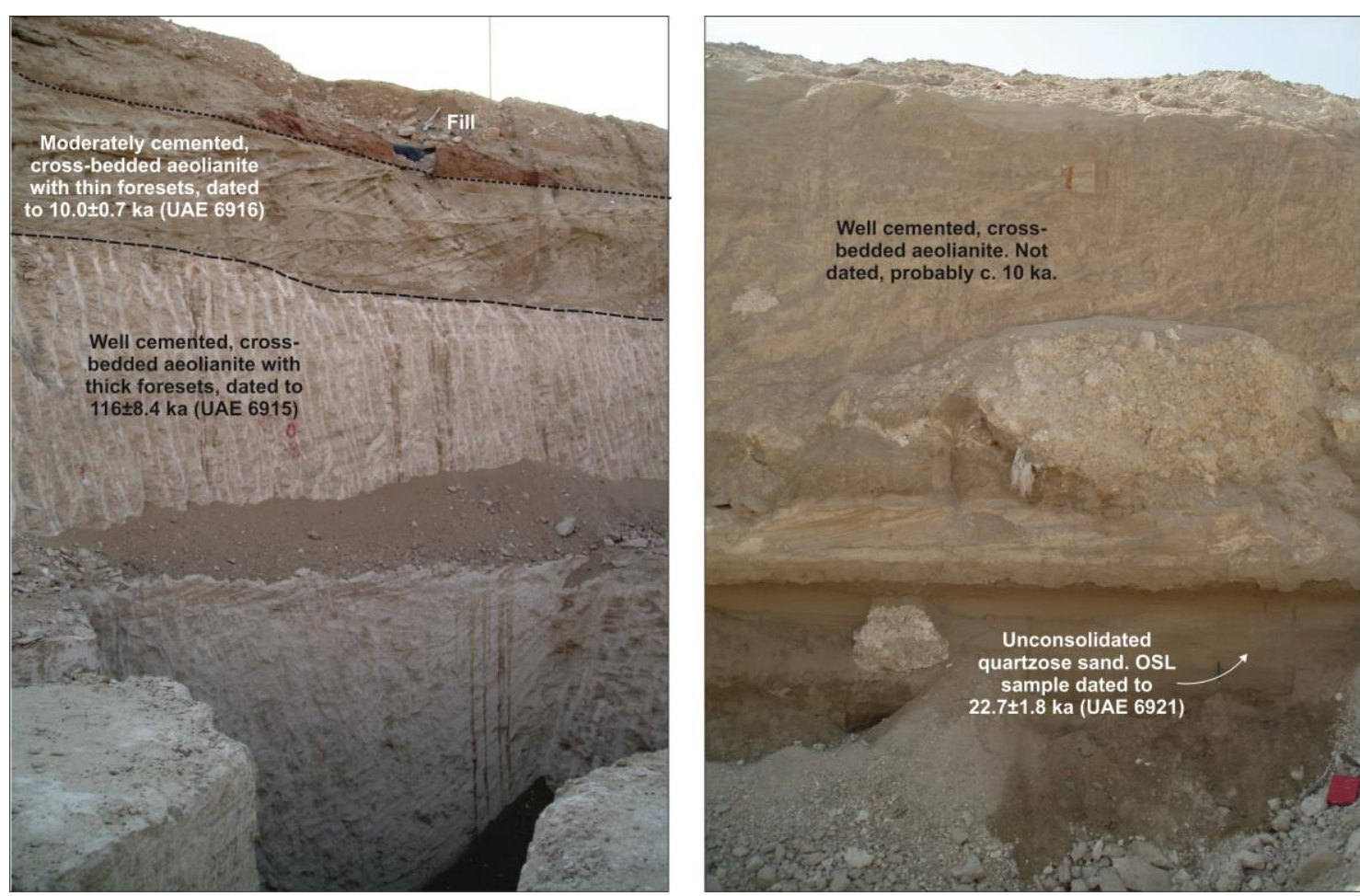

Figure 5. A. Excavation in the Ghayathi Formation near Baniyas, Abu Dhabi [UTM 40266367 2693793], showing two phases of Ghayathi Formation palaeodune deposition dated to $116 \pm 8.4 \mathrm{ka}$ (sample UAE 6915) and at 10.0 $\pm 0.7 \mathrm{ka}$ (sample UAE 6916). B. Section near Mafaq, Abu Dhabi 
[UTM 40253970 2685972] showing well cemented Ghayathi Formation calcarenite overlying unconsolidated quartzose sand dated to $22.7 \pm 1.8 \mathrm{ka}$ (sample UAE 6921). Both figures are from Farrant (2012a).
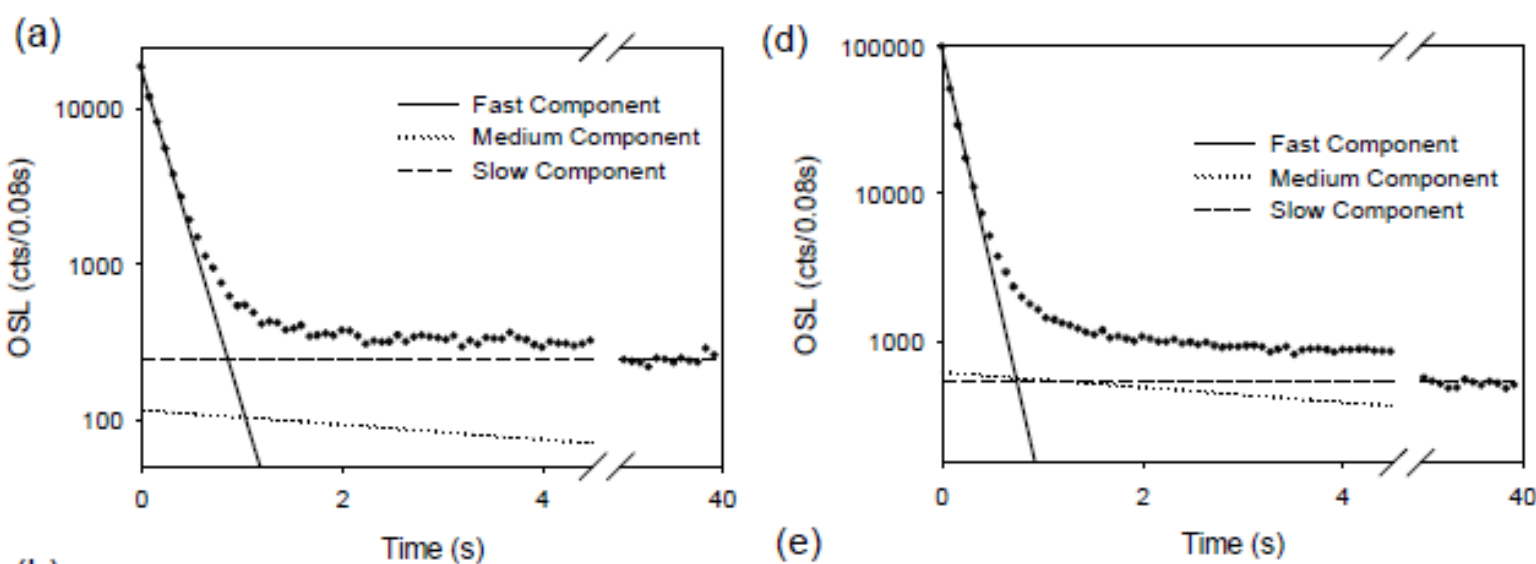

(b)

(e)

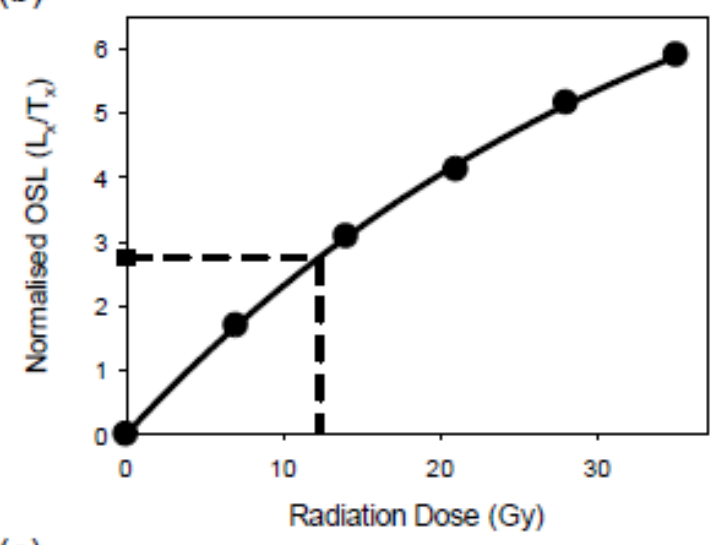

(c)

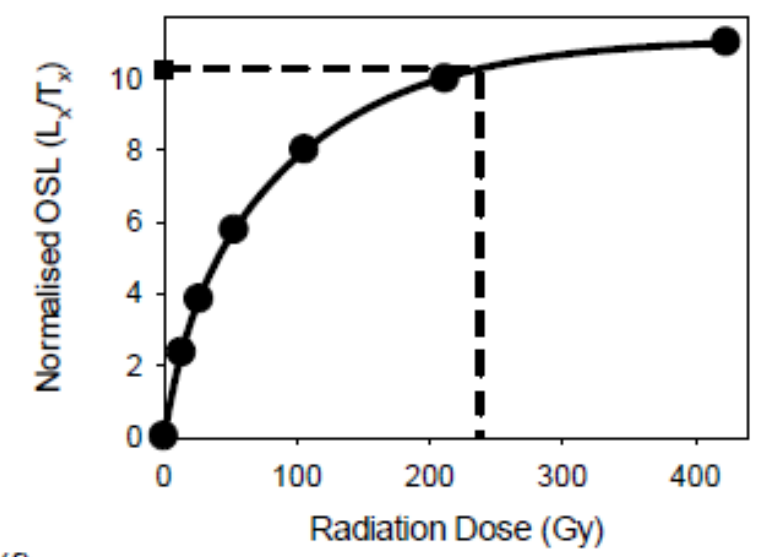

(f)
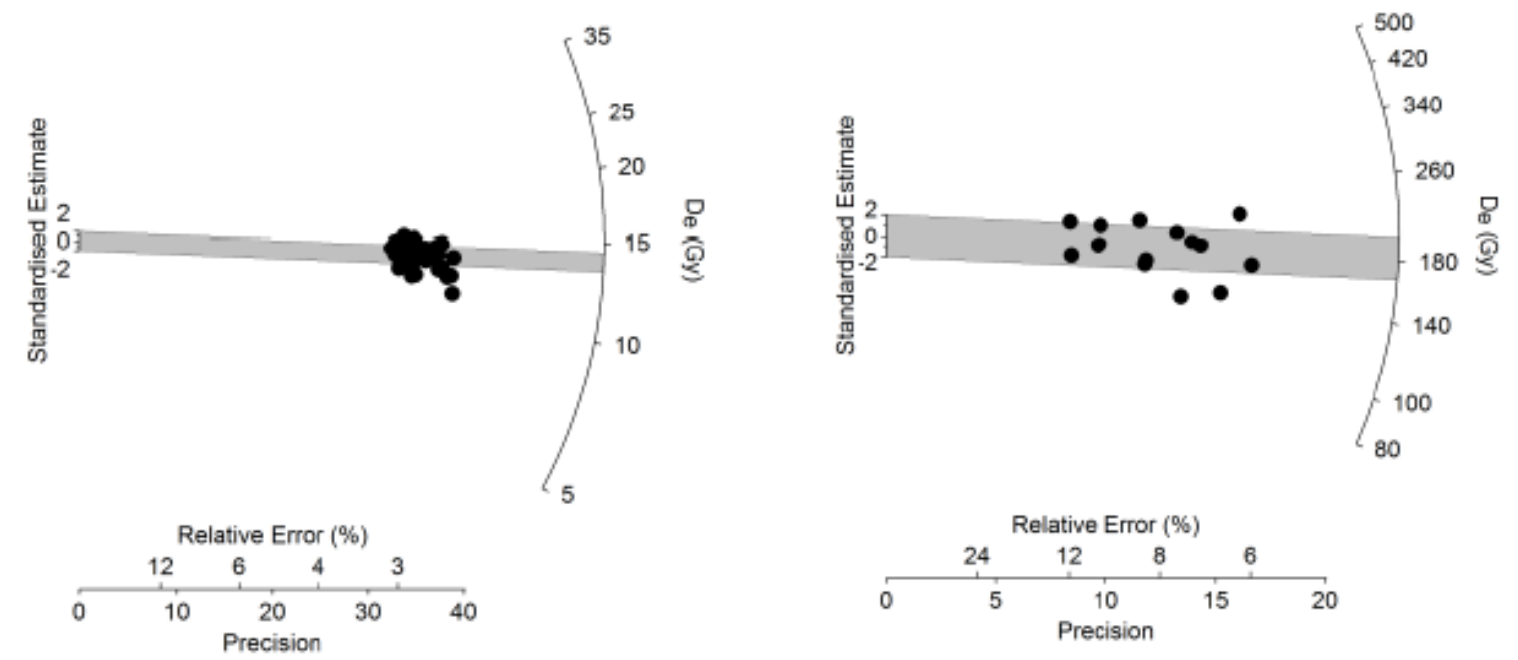

Figure 6: Luminescence data for one of the younger samples reported here UAE 7845 (a-c) and one of the older samples, UAE 7899 (d-f). Typical decay curves are shown for each sample (a and d), along with dose response curves ( $b$ and e) and radial plots of calculated $D_{e}$ values ( $c$ and $f$ ). 


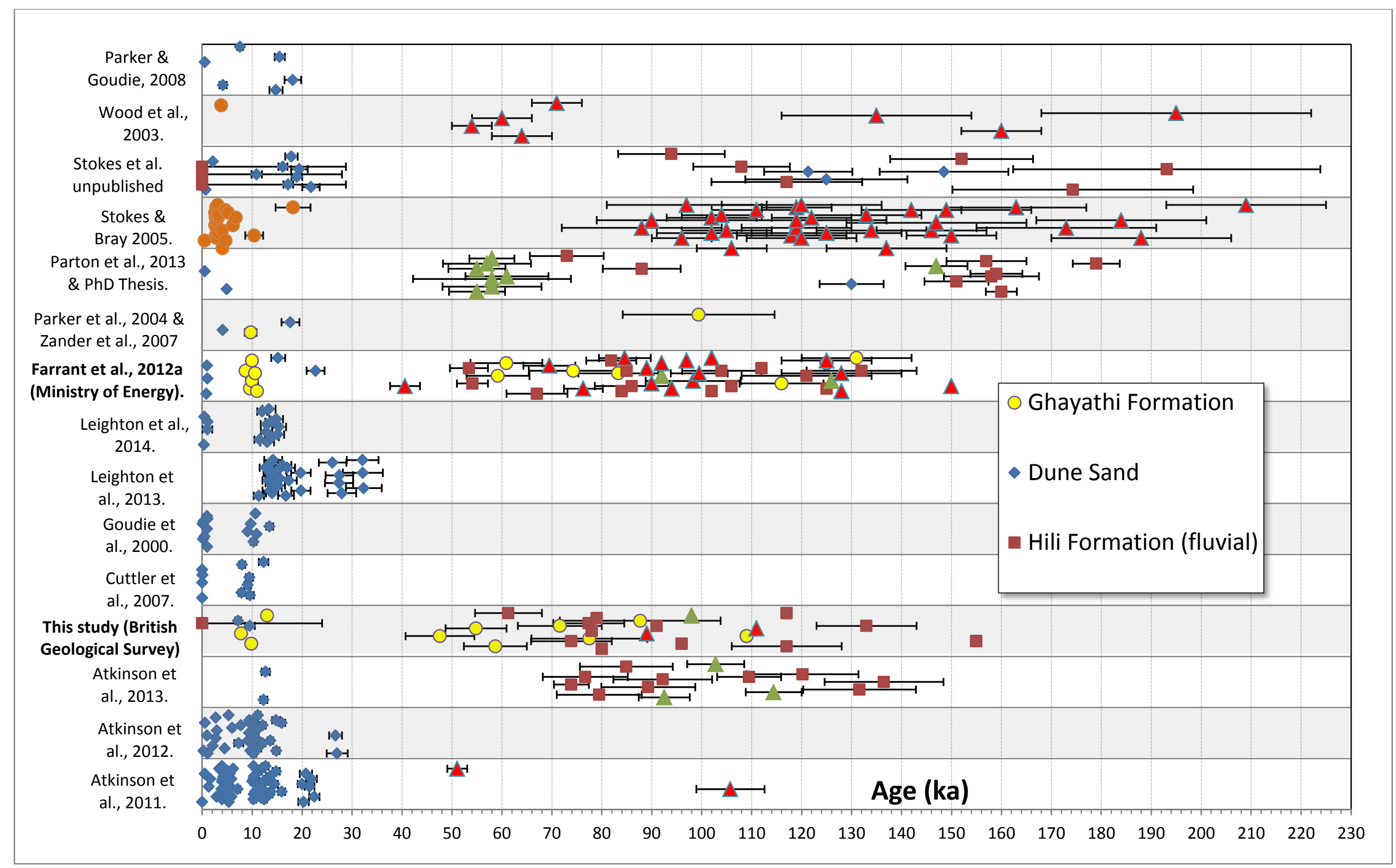

Figure 7. OSL ages grouped by author and lithology. A more detailed discussion of the dune ages during the Holocene can be found in Leighton et al. (2014). 


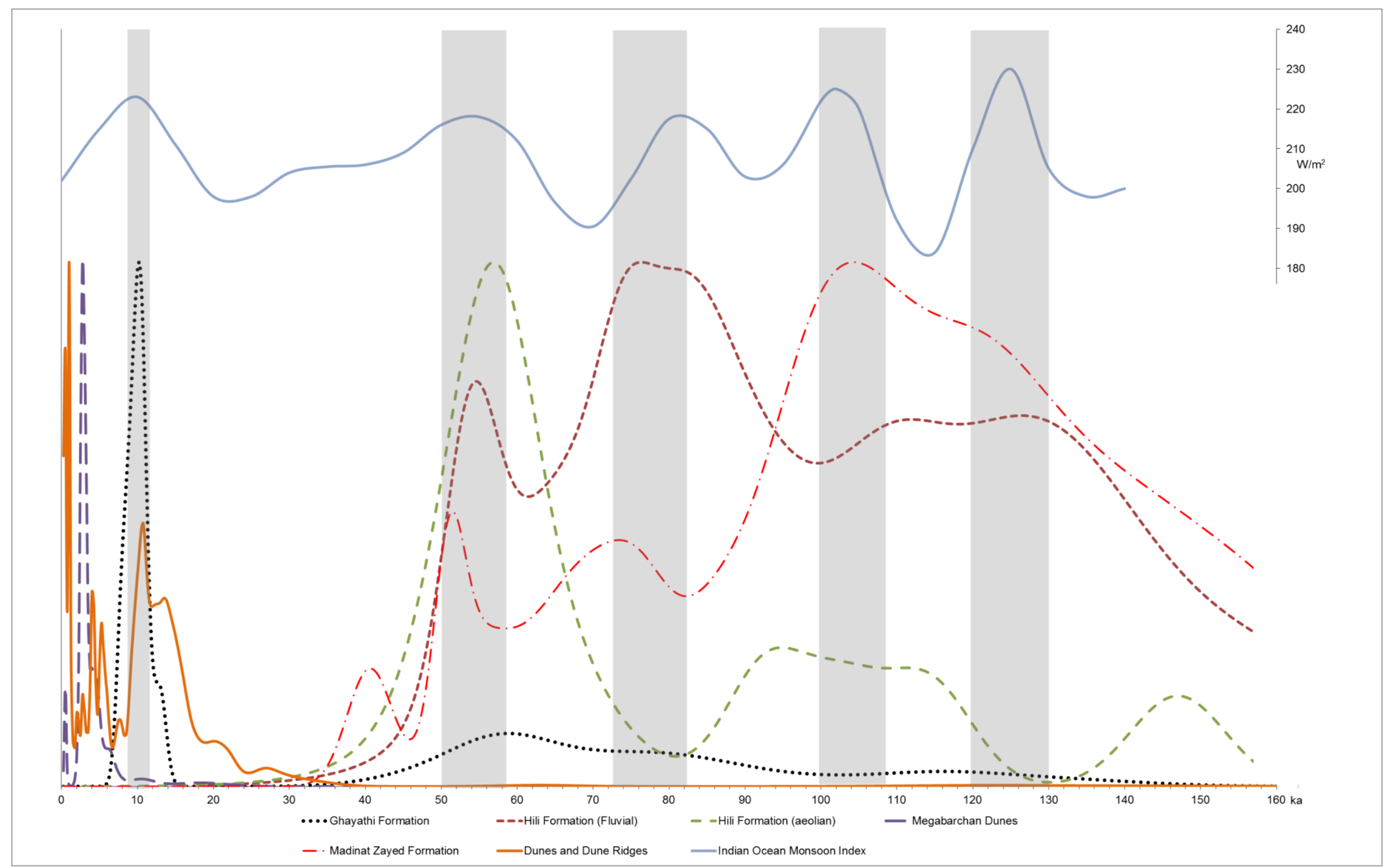

Figure 8. Cumulative probability distribution frequency curve results for each lithological group. The data is normalised, so the magnitude of the peak does not reflect the intensity of the event. The top line is Indian Ocean Monsoon Index (Leuschner and Sirocko, 2003). Shaded bars represent most likely periods of dune stabilisation which can be correlated with humid periods in the Indian Ocean Monsoon Index. 


\begin{tabular}{|c|c|c|}
\hline Author & No of samples & Area \\
\hline This study & 28 & Sites across the UAE, mostly Abu Dhabi emirate. \\
\hline Farrant et al., 2012a & 65 & Sites across the UAE \\
\hline Stokes and Bray, 2005 & 53 & Liwa and central Abu Dhabi \\
\hline Stokes unpublished & 21 & Ras al Khaimah area \\
\hline Parton et al 2014 & 7 & Jebal Faya (Aqabah) \\
\hline Parton PhD thesis & 12 & Al Sibetah quarry, Al Ain \\
\hline Cuttler et al., 2007 & 10 & Southeast UAE (Kharimat Khor Manahil) \\
\hline Leighton et al., 2013 & 28 & Northeast UAE (Ash Shiweb and Ras al Khaimah) \\
\hline Leighton et al., 2014 & 15 & Northeast UAE, Emirates Highway \\
\hline Atkinson et al., 2011 & 53 & Sites in the northeast UAE \& Al Ain \\
\hline Atkinson et al., 2012 & 36 & Sites in the northeast UAE \\
\hline Atkinson et al., 2013 & 15 & Sites in the northeast UAE \& Al Ain \\
\hline Parker et al., 2004 & 2 & Awafi, Ras al Khaimah \\
\hline Parker and Goudie, 2008 & 6 & Al Daith, Ras al Khaimah \\
\hline Goudie et al., 2000 & 14 & Ras al Khaimah \\
\hline Wood et al, 2003 & 8 & Liwa and Madinat Zayed \\
\hline Zander et al., 2007 & 2 & Dubai (Al Soufah) \\
\hline
\end{tabular}

Table 1. Published OSL ages used in this study. Only sources where the location and stratigraphy could be determined were analysed. Six lithological groups have been identified: Dune sand (any unconsolidated aeolian sand with the exception of the Liwa megabarchans); Megabarchans; Ghayathi Formation, Madinat Zayed Formation, and the Hili Formation. The latter can be split into an aeolian and a fluvial component. 


\begin{tabular}{|c|c|c|c|c|c|c|c|}
\hline \multicolumn{8}{|c|}{ A. Samples collected and dated for this study. } \\
\hline Sample & Formation & Easting & Northing & $\begin{array}{c}\text { Total Dose } \\
\text { Rate (Gy/ka) }\end{array}$ & $\begin{array}{c}\text { Number of } \\
\text { aliquots }\end{array}$ & $D_{e}(G y)$ & Age (ka) \\
\hline UAE 7845 & Ghayathi Fm & 276638 & 2682168 & $1.05 \pm 0.06$ & $36(36)$ & $13.7 \pm 0.17$ & $13.0 \pm 0.8$ \\
\hline UAE 7899 & Madinat Zayed Fm & 131442 & 2540446 & $1.50 \pm 0.15$ & $15(24)$ & $>133$ & $>89$ \\
\hline UAE 7901 & Ghayathi Fm & 261042 & 2725460 & $0.98 \pm 0.14$ & $10(24)$ & $46.6 \pm 1.9$ & $47.6 \pm 6.9$ \\
\hline UAE 7903 & Ghayathi Fm & 264338 & 2731184 & $1.02 \pm 0.14$ & $13(24)$ & $79.1 \pm 5.3$ & $77.5 \pm 11.6$ \\
\hline UAE 7906 & Ghayathi Fm & 287057 & 2756163 & $0.72 \pm 0.12$ & $23(24)$ & $62.9 \pm 4.8$ & $87.7 \pm 16.1$ \\
\hline UAE 7909 & Hili Fm & 357344 & 2792224 & $1.20 \pm 0.09$ & $18(24)$ & $>131$ & $>109$ \\
\hline UAE 7910 & Ghayathi Fm & 357344 & 2792224 & $1.04 \pm 0.07$ & $16(24)$ & $76.6 \pm 6.5$ & $73.9 \pm 8.1$ \\
\hline UAE 7915 & Madinat Zayed Fm & 356438 & 2792345 & $1.15 \pm 0.07$ & $14(24)$ & $>128$ & $>111$ \\
\hline UAE 7916 & Hili Fm & 356438 & 2792345 & $1.02 \pm 0.06$ & $21(24)$ & $>158$ & $>155$ \\
\hline UAE 7941 & Hili Fm & 337675 & 2667142 & $0.48 \pm 0.03$ & $17(24)$ & $131 \pm 8.1$ & $273 \pm 24$ \\
\hline UAE 7942 & Hili Fm & 337675 & 2667142 & $1.40 \pm 0.06$ & $18(24)$ & $>112$ & $>80$ \\
\hline UAE 7943 & Hili Fm & 337675 & 2667142 & $1.34 \pm 0.06$ & $20(24)$ & $>104$ & $>78$ \\
\hline UAE 7944 & Hili Fm & 337675 & 2667142 & $1.32 \pm 0.06$ & $21(24)$ & $>127$ & $>96$ \\
\hline UAE 7945 & Hili Fm & 337675 & 2667142 & $1.46 \pm 0.08$ & $23(24)$ & $>116$ & $>79$ \\
\hline UAE 7946 & Hili Fm & 337675 & 2667142 & $0.94 \pm 0.08$ & $18(24)$ & $72.7 \pm 2.6$ & $77.4 \pm 7.1$ \\
\hline UAE 7947 & Hili Fm & 337675 & 2667142 & $1.39 \pm 0.10$ & $24(24)$ & $8.47 \pm 0.23$ & $6.09 \pm 0.47$ \\
\hline UAE 7973 & Ghayathi Fm & 245028 & 2716941 & $0.90 \pm 0.07$ & $9(24)$ & $64.2 \pm 5.6$ & $71.6 \pm 8.4$ \\
\hline UAE 7978 & Ghayathi Fm & 259783 & 2690226 & $1.04 \pm 0.07$ & $22(24)$ & $8.06 \pm 0.36$ & $7.78 \pm 0.65$ \\
\hline UAE 7984 & Ghayathi Fm & 253005 & 2675402 & $0.91 \pm 0.06$ & $15(24)$ & $8.94 \pm 0.46$ & $9.85 \pm 0.81$ \\
\hline UAE 7987 & Hili Fm & 374271 & 2697314 & $1.01 \pm 0.05$ & $21(24)$ & $>118$ & $>117$ \\
\hline UAE 7988 & Hili Fm & 374271 & 2697314 & $1.01 \pm 0.05$ & $22(24)$ & $135 \pm 6.7$ & $133 \pm 10$ \\
\hline UAE 7989 & Hili Fm & 374271 & 2697314 & $1.13 \pm 0.06$ & $20(24)$ & $>111$ & $>98$ \\
\hline UAE 7990 & Hili Fm & 374271 & 2697314 & $1.01 \pm 0.07$ & $21(24)$ & $118 \pm 7.9$ & $117 \pm 11$ \\
\hline UAE 7991 & Hili Fm & 374271 & 2697314 & $1.38 \pm 0.14$ & $20(24)$ & $84.7 \pm 3.7$ & $61.3 \pm 6.7$ \\
\hline UAE 8008 & Ghayathi Fm & 233382 & 2702565 & $0.98 \pm 0.07$ & $12(24)$ & $57.7 \pm 4.5$ & $58.7 \pm 6.3$ \\
\hline UAE 8026 & Ghayathi Fm & 162353 & 2659413 & $1.06 \pm 0.08$ & $22(24)$ & $58.0 \pm 4.7$ & $54.8 \pm 6.1$ \\
\hline
\end{tabular}


Table 2. OSL data for samples collected during this study. Grid references are in UTM Format, Zone 40, WGS84. The number of aliquots indicates the number of aliquots that passed all the acceptance criteria described in the text and which yielded De values used in age calculation. The figures in parentheses are the total number of aliquots measured. Sample metadata is available in the supplementary data. 